Article

\title{
High-Performance Thin-Film-Nanocomposite Cation Exchange Membranes Containing Hydrophobic Zeolitic Imidazolate Framework for Monovalent Selectivity
}

\author{
Jian $\mathrm{Li}^{1}{ }^{1}$, Zhijuan Zhao ${ }^{1,2}$, Shushan Yuan ${ }^{1}$, Junyong Zhu ${ }^{1}$ and Bart Van der Bruggen ${ }^{1,3, *}$ \\ 1 Department of Chemical Engineering, KU Leuven, Celestijnenlaan 200F, B-3001 Leuven, Belgium; \\ jian.li@kuleuven.be (J.L.); zhijuan.zhao@student.kuleuven.be (Z.Z.); shushan.yuan@kuleuven.be (S.Y.); \\ junyong.zhu@kuleuven.be (J.Z.) \\ 2 University of Chinese Academy of Sciences, Beijing 100049, China \\ 3 Faculty of Engineering and the Built Environment, Tshwane University of Technology, Private Bag X680, \\ Pretoria 0001, South Africa \\ * Correspondence: bart.vanderbruggen@kuleuven.be; Tel.: +32-163-223-40
}

Received: 16 April 2018; Accepted: 9 May 2018; Published: 10 May 2018

\begin{abstract}
Zeolitic imidazolate framework-8 (ZIF-8) offers good hydrothermal, chemical, and thermal stabilities, and is therefore of interest in membrane synthesis. In this work, an interfacial polymerization (IP) method was applied by anchoring ZIF-8 to the skin layer of thin-film nanocomposite (TFN) membranes in order to obtain monovalent selectivity in electrodialysis. Organic trimesoyl chloride (TMC, $0.1 \mathrm{wt} \%$ ) solutions and aqueous m-phenyl diamine (MPD, $2 \% \mathrm{w} / \mathrm{v}$ ) solutions were used during the interfacial polymerization process. A range of polyamine (PA)/ZIF- 8 based membranes was fabricated by varying the concentration of ZIF-8 in the organic solution. The properties of the primary and modified membrane were characterized by scanning electron microscope (SEM), energy dispersive X-ray analysis (EDAX), atomic force microscopy (AFM), water uptake, ion exchange capacity, and contact angle measurements. No significant changes of the surface structure of the PA/ZIF-8 based membranes were observed. Nevertheless, the presence of ZIF-8 under the PA layer plays a key role in the separation process. For single salt solutions that were applied in electrodialysis (ED), faster transport of $\mathrm{Na}^{+}$ and $\mathrm{Mg}^{2+}$ was obtained after introducing the ZIF-8 nanoparticles, however, the desalination efficiency remained constant. When the hybrid membranes were applied to electrodialysis for binary mixtures containing $\mathrm{Na}^{+}$as well as $\mathrm{Mg}^{2+}$, it was demonstrated that the monovalent selectivity and $\mathrm{Na}^{+}$flux were enhanced by a higher ZIF-8 loading.
\end{abstract}

Keywords: electrodialysis; ZIF-8; interfacial polymerization; desalination; monovalent selectivity

\section{Introduction}

Population growth and economic development have resulted in global water challenges. Already today, $50 \%$ of the world population are suffering medium water shortage, while $10 \%$ are undergoing extreme water problems [1]. Moreover, it is expected that the global population would grow by nearly $40 \%$ in the next forty years [2]. During the Global Risks 2015 Report of the World Economic Forum, water shortage had been identified as the most serious challenge for human beings in the next few decades [3]. The improved demand for water sources has posed a worldwide threat to water supply systems. More than seventy percent of the Earth's surface is covered by water, but the available freshwater only accounts for a tiny fraction of the earth's total water supply [4]. The available drinking water that is obtained from groundwater and lakes is limited because much of it is too deep to access or cannot be exploited in a sustainable way. Furthermore, severe ecosystem damage caused water depletion at a striking rate across the world [5]. Oceans, containing the most abundant 
water resources on the earth, can provide an inexhaustible, continuous, and high-quality water supply without damaging the original freshwater ecosystems [6]. Thus, developing advanced water treatment technologies for desalination is imperative.

Over the past decades, membrane technology for water desalination has rapidly changed from an academic pursuit to commercial reality. When compared with reverse osmosis (RO), electrodialysis (ED) is the most commonly applied process for the production of drinking and process water. Electrodialysis, as an electrochemical separation process, is the most economic process using ion exchange membranes (IEMs) for producing drinking water when the salinity of target water is less than $5 \mathrm{~g} / \mathrm{L}$. In order to generate high quality water to meet the requirements of specific industrial processes, membranes with selectivity for given ions are critical. Monovalent selectivity is governed by the affinity towards the fixed charge groups and the migration speed within the membrane matrix [7]. Based on these effects, IEMs with selectivity for specific ions have been explored, by including a thin charged skin layer or by generating a compact functional layer on the surface of IEMs. Thin film composite (TFC) membranes, comprising an ultrathin separating barrier layer that was prepared by interfacial polymerization on top of a membrane, could be used in electrodialysis for the purpose of separating multivalent ions from a mixed solution containing monovalent and multivalent ions [8]. However, the inevitably higher area resistance that is caused by a surficial functional layer increases the energy consumption at the same time. In recent years, thin film nanocomposite (TFN) membrane emerged as a new type of composite membranes, have been widely studied and industrially applied. Nanoparticles are incorporated within the interfacial layer of the TFC membrane, with the aim of enhancing the properties of the surface layer, such as hydrophilicity, permeability, selectivity, stability, and surface charge density [9]. Currently, TFNs are widely used in forward osmosis (FO), reverse osmosis (RO), and nanofiltration (NF) [10-12]. However, they are seldom applied in electromembrane processes.

Metal-organic frameworks (MOFs), as a class of hybrid inorganic-organic solid compounds, has gained interest due to their structural and functional tunability [13]. They can serve as porous materials similar to zeolites, while having a better affinity for the polymeric chains [14]. In addition, the flexibility in pore size of MOFs can be controlled by choosing appropriate organic ligands and inorganic secondary building units, which significantly broadens their application in molecular sieving. Zeolitic imidazolate frameworks (ZIFs) are a subclass of MOFs with large surface areas and pore volumes. Notably, ZIF-8, which was obtained by the reaction of $\mathrm{Zn}^{2+}$ with 2-methylimidazole as linker, has gained great interest in membrane utilization due to its high chemical and thermal stability [14-16]. Duan et al. added $0.4 \%$ (w/v) ZIF-8 nanoparticles to a TFN membrane with an $162 \%$ permeance increase while maintaining a high salt rejection [17]. However, the interfacial nanogaps that were present in the functional layer of the decorated membrane cannot be fully avoided [18]. ZIF- 8 has a small aperture with a size of $3.4 \AA$ and a comparatively large cavity with a size of $11.6 \AA$ [19]. The small aperture of ZIF-8 can serve as an effective filter to separate hydrated cations of $\mathrm{Mg}^{2+}(4.28 \AA)$ through a size sieving effect $[20,21]$. Although there is a significant variation on the reported values of hydrated $\mathrm{Na}^{+}$(between 2.99 and $3.58 \AA$ ), in general, the hydrated cations with larger crystal radii have weaker hydration shells, so that the detachment of the hydration shell would occur when ions pass the solution-membrane interface [22,23]. Consequently, ZIF-8 has the right size to separate dehydrated $\mathrm{Na}^{+}(0.95 \AA)$ and hydrated $\mathrm{Mg}^{2+}[24,25]$.

Different from the previously reported strategy to form a dense cationic charged layer by chemical modification, this study presents an interfacial polymerization strategy with nanoparticles to separate monovalent and multivalent ions. Porous ZIF-8 was used as a nanofiller underneath the surficial functional layer to separate monovalent ions. The influence of the ZIF-8 content on the desalination performance was explored to determine the optimal preparation parameters. 


\section{Materials and Methods}

\subsection{Materials}

Ion exchange membranes that were used during the experiments were supplied by Fujifilm Manufacturing Europe B.V (Tilburg, The Netherlands). Sodium chloride ( $\mathrm{NaCl}, \geq 99.5 \%)$, magnesium chloride $\left(\mathrm{MgCl}_{2}, \geq 99.8 \%\right)$, sodium sulfate $\left(\mathrm{Na}_{2} \mathrm{SO}_{4}, \geq 99 \%\right)$, trimesoyl chloride (TMC, $\left.\geq 98 \%\right)$, m-phenylenediamine (MPD, $\geq 99 \%$ ), and hexane (anhydrous, 95\%) were acquired from Sigma-Aldrich (Overijse, Belgium). Basolite ${ }^{\circledR}$ Z1200 (ZIF-8) was produced by BASF (Antwerpen, Belgium) and acquired from Sigma-Aldrich. Deionized (DI) water was applied throughout the experiments. All of the reagents and solvents were commercially available and were used as received.

\subsection{Membrane Preparation}

The monovalent cation exchange membranes were prepared by an IP method on commercial Fuji films. The membranes were first soaked in distilled water for one day to remove the impurities and then fixed in a lab-made device for interfacial polymerization. MPD concentration was fixed at $2.0 \%(\mathrm{w} / \mathrm{v})$. Organic phase solutions that were used in these experiments were prepared via weighing specific amount of ZIF-8 to the TMC/n-hexane solution (0.1 wt \%) under sonication for $1 \mathrm{~h}$. The as-prepared membranes with different ZIF-8 loadings $(0.00 \%, 0.02 \%, 0.04 \%, 0.06 \%$, and $0.08 \%$ in $50 \mathrm{~mL}$-hexane solution) were designated as M-1, M-2, M-3, M-4, and M-5. The commercial cation exchange membrane was first immersed into the aqueous solutions for 5 min to implement the adsorption of MPD. After removing the remaining aqueous solutions on the membrane surface, the organic phase solution with a specific amount of ZIF-8 was poured on the surface of the membrane to execute the polymerization, and ZIF-8 anchoring process for $2 \mathrm{~min}$. After the organic solution was removed, the excess organic solution was drained at the fume hood. The fresh prepared membrane was washed three times with n-hexane and dried completely to enhance the surface layer stability.

\subsection{Characterization and Performance Assessment}

The surface morphology of the prepared membranes was observed by using a Philips scanning electron microscope XL30 FEG (SEM, Eindhoven, The Netherlands). The membrane samples were first dried in an oven and then attached on a holder before sputtering. SEM detection was working at $10 \mathrm{kV}$. Elemental analysis of the membrane surface was conducted using EDAX that was equipped with a PGT-IMIX PTS EDX system. The surface roughness information of the membranes with and without ZIF-8 were revealed by a Dimension FastScan AFM device (Bruker, Karlsruhe, Germany) with scan areas of $1 \mu \mathrm{m} \times 1 \mu \mathrm{m}$ under ambient conditions. The surface wetting nature of the membranes was characterized at room temperature via a contact angle system (OCA20, Dataphysics Instruments, Filderstadt, Germany). A circle fitting method was utilized by drop shape analysis software. The membrane resistance was determined by electrochemical impedance spectroscopy (EIS, Solartron Electrochemical System), within the frequency range from $1 \mathrm{kHz}$ to $1 \mathrm{MHz}$ at a $0.5 \mathrm{M} \mathrm{NaCl}$ solution. The water uptake was calculated by Equation (1):

$$
W U=\frac{W_{\text {wet }}-W_{d r y}}{W_{d r y}} \times 100 \%
$$

where $W_{\text {wet }}$ and $W_{d r y}$ are the mass of wet and dry membranes, respectively. The ion exchange capacity (IEC) of the prepared monovalent cation exchange membranes was detected by the titration method. The membrane was immersed in a $1 \mathrm{M} \mathrm{HCl}$ solution to saturate it with $\mathrm{H}^{+}$, and then the membrane was transferred to a $1 \mathrm{M} \mathrm{NaCl}$ solution for $24 \mathrm{~h}$ to liberate the $\mathrm{H}^{+}$ions. The released $\mathrm{H}^{+}$ions concentration was quantified by a $0.01 \mathrm{M} \mathrm{NaOH}$ solution. The IEC was calculated based on the following equation:

$$
I E C=\frac{n_{H^{+}}}{W_{d r y}}
$$


where $n_{H^{+}}$is the concentration of the released $\mathrm{H}^{+}$ions and $W_{d r y}$ is the dry membrane weight $(\mathrm{g})$. Surface charge was detected by a zeta potential that was equipped with a Surpass 3 (Anton Paar, Graz, Austria). The results were obtained in a $1 \mathrm{mM} \mathrm{KCl}$ electrolyte solution $(\mathrm{pH}=6.0)$. Diffusion dialysis experiments were conducted using a $1 \mathrm{M} \mathrm{NaCl}$ solution and distilled water as feed side and permeate side, respectively. The effective membrane area was $13.8 \mathrm{~cm}^{2}$. Both of the compartments were vigorously stirred to minimize the effect of concentration polarization. The permeate side conductivity was recorded every $10 \mathrm{~min}$ to determine the concentration changes.

The selectivity of the monovalent cation exchange membranes was assessed by electrodialysis experiments. In order to deeply understand the transfer of cations during the electrodialysis process, single salt solution desalting experiments were conducted to evaluate the flux of single ions. Three streams were circulated in the ED stack: the concentrate, diluate and the electrode rising solution. The ED setup that was used in this experiment is the same as reported elsewhere [26]. The diluate and concentrate compartment were filled with $150 \mathrm{~mL} 2 \mathrm{~g} / \mathrm{L} \mathrm{NaCl} / \mathrm{MgCl}_{2} .1 \mathrm{~L} 20 \mathrm{~g} / \mathrm{L}$ $\mathrm{Na}_{2} \mathrm{SO}_{4}$ was used as the electrode rinsing solution with a constant flow rate of $30 \mathrm{~L} / \mathrm{h}$. The effective surface area of the membrane was $19.6 \mathrm{~cm}^{2}$. The ED experiment was carried out at a current density of $15.3 \mathrm{~mA} \mathrm{~cm}^{-2}$.

The cation flux across the ion exchange membrane was calculated from the concentration change with time $(d C / d t)$, based on the following equation:

$$
J_{C}\left(m o l / \mathrm{cm}^{2} \cdot s\right)=\frac{V}{A}\left(\frac{d C}{d t}\right)
$$

where $V$ is the volume $\left(\mathrm{cm}^{3}\right)$ of the concentrate solution and $A$ is the effective surface area of membrane $\left(\mathrm{cm}^{2}\right)$.

The monovalent selectivity of the membrane was measured on the same apparatus. A solution with $0.05 \mathrm{M} \mathrm{MgCl}_{2}$ and $0.5 \mathrm{M} \mathrm{NaCl}$ was used as diluate compartment and a $0.5 \mathrm{M} \mathrm{NaCl}$ was used as concentrate compartment. The concentration of $\mathrm{Na}^{+}$and $\mathrm{Mg}^{2+}$ in the diluate compartment was measured by cation chromatography after $60 \mathrm{~min}$. The monovalent selectivity was calculated based on the ratio of monovalent and divalent cation fluxes [27].

\section{Results and Discussion}

\subsection{SEM and Zeta Potential}

The surface morphology of the prepared membranes with different ZIF-8 contents are displayed in Figure 1. The surface of the primary Fujifilm membrane was flat, whereas that of a MPD/TMC membrane (M-1) exhibited the typical ridge-and-valley feature. This phenomenon resulted from the violent reaction between small molecular amine and acyl chloride. With increasing ZIF-8 loading to the surface layer, the membrane showed a more net-like structure with denser and smoother zones. At higher ZIF-8 loadings, especially at $0.08 \%$, more "cubic" structures are visible, which represent ZIF-8 nanoparticles that are covered by polyamide. No direct relation between the morphology and the ZIF-8 concentration was observed, indicating that nanoparticles were covered by a continuous PA film. It is believed that interfacial polymerization is a diffusion control process. MPD adheres on the membrane surface and diffuses and reacts with TMC in the organic phase. When no MPD permeates across the barrier layer, the reaction stops. For the monovalent ion exchange membrane that was prepared with ZIF-8 nanoparticles, ZIF-8 deposits on the membrane first and it is embedded under the PA layer, leading to similar SEM images [15]. The elemental weight distribution on the membrane surface was determined by EDAX to confirm the presence of ZIF-8. In Table 1, a low Zn content can be observed. With increasing concentration of ZIF-8 nanoparticles, a higher Zn content can be achieved. The EDAX mapping (Figure 2) demonstrated a uniform distribution of ZIF-8 on the membrane surface. However, the variation of the $\mathrm{Zn}$ concentration is not obvious. Thus, the results of SEM and EDAX suggest a successful encapsulation of ZIF-8 nanoparticles. The PA surface structures with various 
crosslinking degree can be explored by analyzing the element ratios between $\mathrm{O}$ and $\mathrm{N}$. For the modified membrane without ZIF-8 nanoparticles, the $\mathrm{O} / \mathrm{N}$ ratio is about 1.75 . It was obvious that no distinct difference can be seen in the $\mathrm{O} / \mathrm{N}$ ratio with the increase of ZIF- 8 concentration. This indicated that the crosslinking degree of MPD/TMC copolymer was maintained as stable, while the ZIF-8 concentration is below $0.08 \%$. The zeta potential of the as-prepared membranes was listed in Table 2 . Both the primary ion exchange membrane and the MPD/TMC modified membrane are negatively charged, with zeta potentials of -16.4 and $-20.3 \mathrm{mV}$, respectively. After introducing ZIF-8 into the selective layer, the zeta potential of the modified membrane shifted to $-22.3 \mathrm{mV}$. With a further increasing ZIF-8 content, the zeta potential values continued to decrease. It should be noticed that the slight reduction of zeta potential is not consistent with the $\mathrm{O} / \mathrm{N}$ ratio results that were obtained from EDAX, which can be explained by the detection depth of EDAX. A detection depth around $1 \mu \mathrm{m}$ for EDAX with complex background can reduce the impact of carboxylic acid groups on $\mathrm{O} / \mathrm{N}$ ratio. Thus, the ZIF-8 loading inside the MPD/TMC surface layer could generate more carboxylic acid groups.
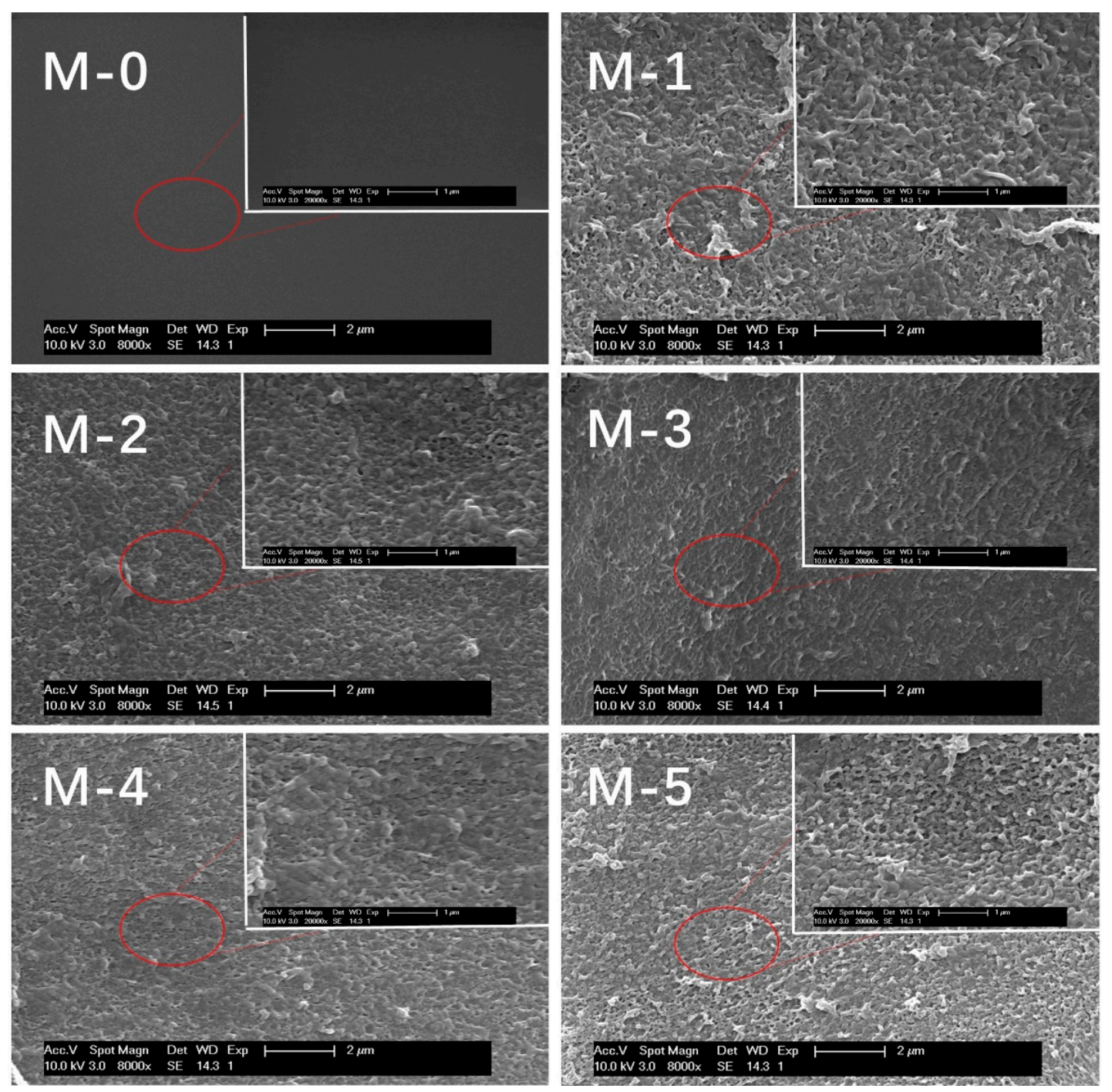

Figure 1. Scanning electron microscope (SEM) images of the unmodified and modified ion exchange membrane. Nanoparticle loadings are (M-1) 0.00\%, (M-2) 0.02\%, (M-3) 0.04\%, (M-4) 0.06\%, and (M-5) $0.08 \%(\mathrm{w} / \mathrm{v})$. 


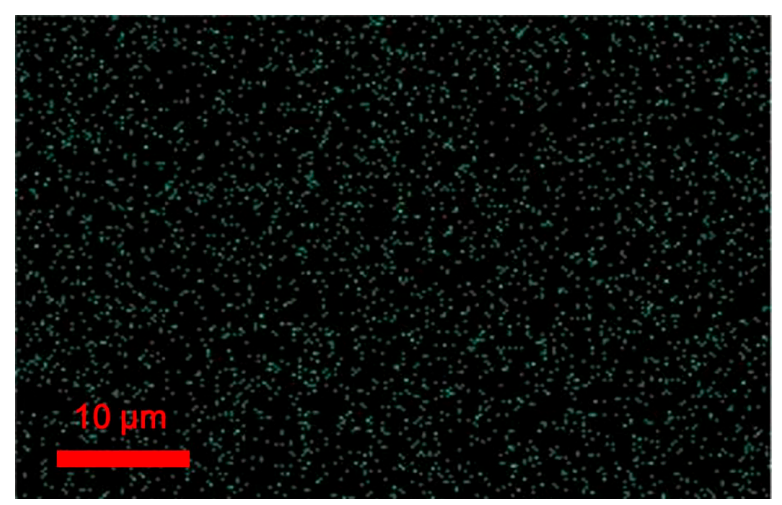

Figure 2. Energy dispersive X-ray analysis (EDAX) mapping for the membrane after Zeolitic imidazolate framework-8 (ZIF-8) incorporation (Light dots are of Zn).

Table 1. Atomic concentrations of C, N, O, and Zn obtained by EDAX results.

\begin{tabular}{ccccc}
\hline Membrane Type & C (\%) & N (\%) & O (\%) & Zn (\%) \\
\hline M-0 & 56.80 & 14.31 & 28.89 & - \\
M-1 & 59.35 & 14.78 & 25.87 & - \\
M-2 & 57.59 & 16.60 & 25.78 & 0.03 \\
M-3 & 57.77 & 16.14 & 26.01 & 0.08 \\
M-4 & 58.30 & 16.92 & 24.70 & 0.08 \\
M-5 & 59.07 & 15.49 & 25.32 & 0.12 \\
\hline
\end{tabular}

Table 2. Zeta potential results of the primary and modified membranes.

\begin{tabular}{ccccccc}
\hline Membrane & M-0 & M-1 & M-2 & M-3 & M-4 & M-5 \\
\hline Zeta potential $(\mathrm{mV})$ & -16.4 & -20.7 & -22.3 & -23.7 & -23.8 & -24.5 \\
\hline
\end{tabular}

The water contact angle measurements also confirmed the presence of ZIF- 8 under the PA film (Figure 3). After modification, contact angles increased from $27.6^{\circ}$ to $43.7^{\circ}$. This indicates that the primary commercial cation exchange membranes are highly hydrophilic; by introducing the MPD/TMC layer, the surface becomes more hydrophobic. The addition of a certain content of ZIF-8 nanoparticles to the TFN membranes greatly reduce the surface hydrophilicity, which is in accordance with previous research [28]. Assuming that some ZIF-8 nanoparticles would be bared on the modified layer, water contact angles would increase with the increase of the ZIF-8 nanoparticles content. However, a comparatively more hydrophilic surface was obtained with increasing ZIF-8 nanoparticles content, which means that ZIF-8 nanoparticles tend to be covered by the polyamide layer $[17,28]$. As was proved by previous zeta potential results, increased ZIF-8 loadings suggest an increased surface charge density of the MPD/TMC surface layer, and thus increased carboxylic acid groups lead to an increased hydrophilicity. Furthermore, the increased roughness could also enhance the hydrophilicity to some extent [29]. As shown in Figure 4 and Table 3, the pristine membrane has a smooth surface, with a roughness of $1.0 \mathrm{~nm}$. After modification, the $\mathrm{R}_{\mathrm{sq}}$ significantly increases to $36.3 \mathrm{~nm}$. By raising the initial concentration of ZIF-8 to $0.08 \%$, the surface roughness increased to $70.8 \mathrm{~nm}$, with the contact angles decreasing from $78^{\circ}$ to $71^{\circ}[30,31]$. As a consequence, a further increase of ZIF-8 nanoparticles loadings tends to reduce the contact angles. 


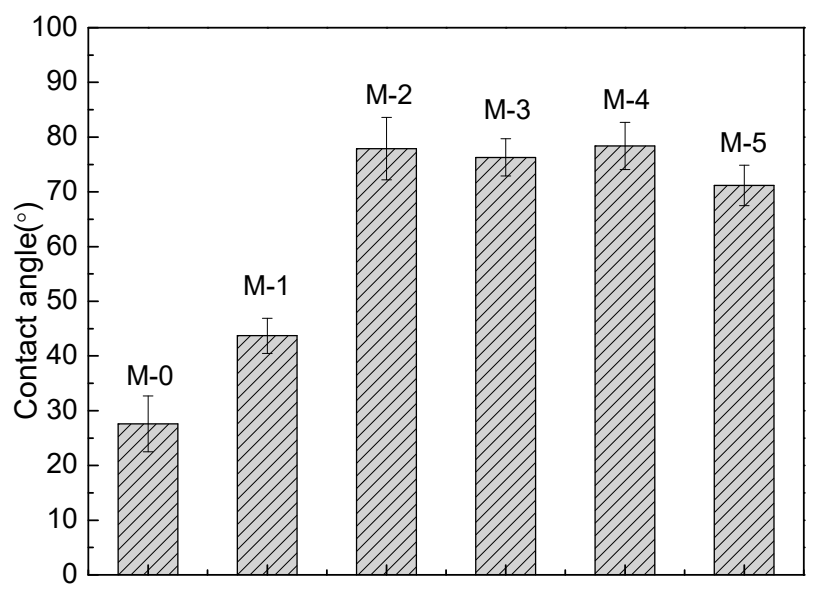

Figure 3. Contact angle of the modified ion exchange membranes.
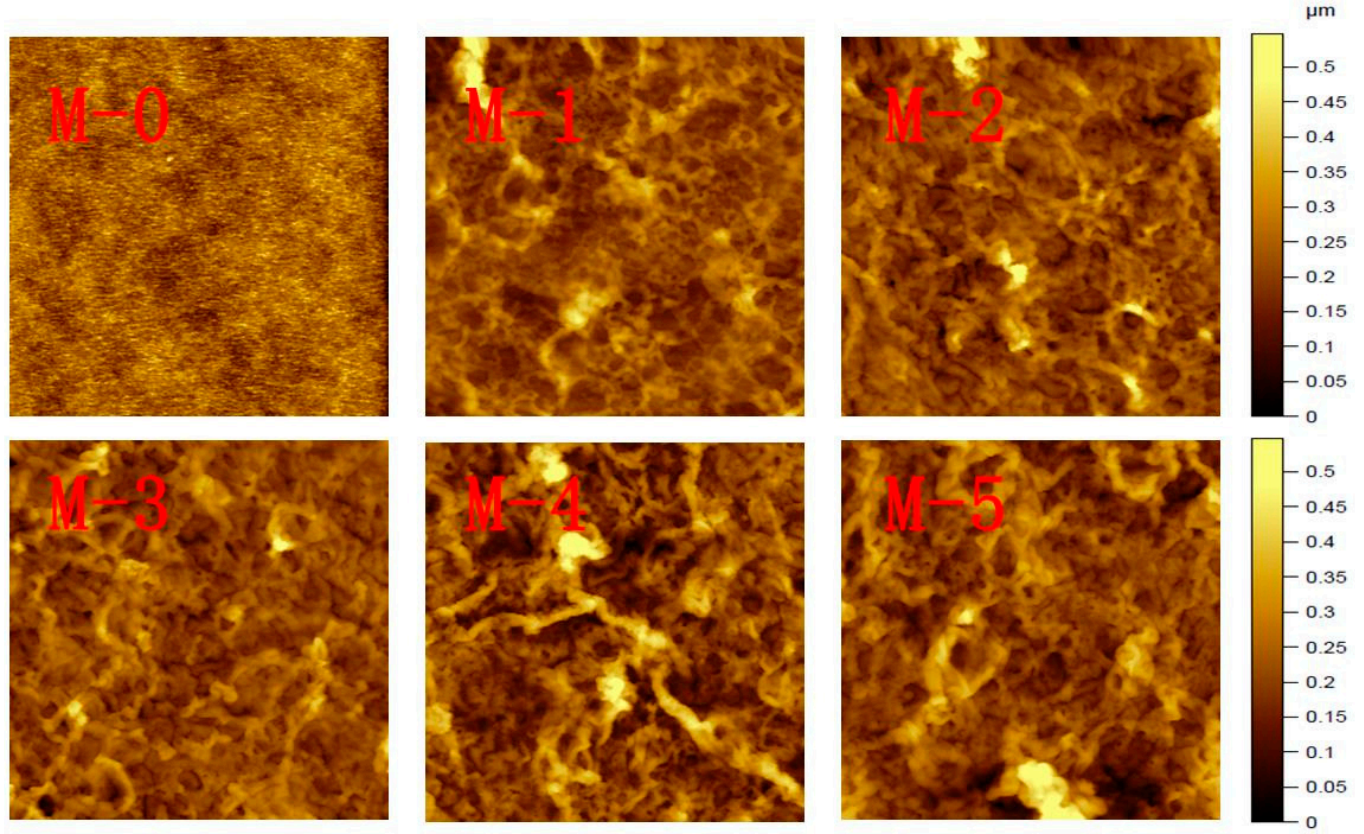

Figure 4. Atomic force microscopy (AFM) topography of the membrane with and without modification.

Table 3. AFM surface roughness parameters of the pristine and modified membranes.

\begin{tabular}{ccccccc}
\hline Membrane Type & M-0 & M-1 & M-2 & M-3 & M-4 & M-5 \\
\hline Root mean square height $\left(\mathrm{R}_{\mathrm{sq}}\right)$ & $1.0 \mathrm{~nm}$ & $36.3 \mathrm{~nm}$ & $43.4 \mathrm{~nm}$ & $51.5 \mathrm{~nm}$ & $65.2 \mathrm{~nm}$ & $70.8 \mathrm{~nm}$ \\
Maximum height $\left(\mathrm{R}_{\mathrm{sz}}\right)$ & $4.4 \mathrm{~nm}$ & $210 \mathrm{~nm}$ & $230 \mathrm{~nm}$ & $274 \mathrm{~nm}$ & $347 \mathrm{~nm}$ & $335 \mathrm{~nm}$ \\
\hline
\end{tabular}

\subsection{IEC and Water Uptake}

The ion-exchange capacity is yields the ionic conductivity of the membranes, while the water uptake can affect the transport behavior of ions across the membrane. The IEC and the water uptake values as a function of ZIF-8 content for all of the prepared membranes are presented in Figure 5 . Changes of the IEC and water uptake values can be observed after surface modification of the MPD/TMC layer from $1.34 \mathrm{mmol} / \mathrm{g}$ to $1.42 \mathrm{mmol} / \mathrm{g}$ and $33.4 \%$ to $30.6 \%$, respectively. Since MPD/TMC composites are negatively charged [32], the IEC was increased after introducing more negative functional groups. The dense structure of the MPD/TMC layer is more hydrophobic, which indicates the reduced water molecular accessibility to the surface matrix. Therefore, an increased IEC and 
reduced water uptake for the MPD/TMC modified membrane was obtained. Furthermore, all of the membranes exhibited an increase in IEC and water uptake with increasing ZIF-8 content. Besides, a large cavity of ZIF-8 that can accommodate water molecules, which can be another factor that contributed to the higher water uptake. Consequently, the prepared PA/ZIF-8 membrane surface has an enhanced water uptake, and a more negative charge density with increased ZIF-8 content.

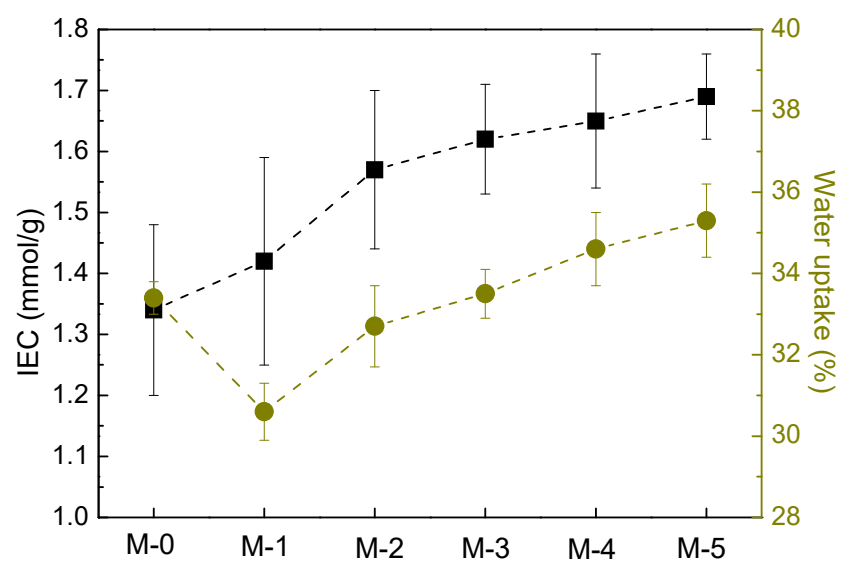

Figure 5. Ion exchange capacity (IEC) and water uptake of the membranes with different ZIF-8 loadings.

\subsection{Diffusion Dialysis}

Diffusion dialysis using the synthesized membranes with different ZIF-8 content was carried out to study the diffusional ion transport process. In Figure 6, it can be seen that the conductivity of the permeate side increases during the experiments, which is caused by the diffusion of ions from the high concentration chamber to the low concentration chamber. However, the rate of conductivity change is different. After $1 \mathrm{~h}$ self-diffusion, the conductivity of the M-0 membrane changed from $10 \mu \mathrm{s} / \mathrm{cm}$ to $275 \mu \mathrm{s} / \mathrm{cm}$. The interfacial polymerization between MPD and TMC limited the diffusion process; as a result, the diffusion of $\mathrm{NaCl}$ for the $\mathrm{M}-1$ membrane becomes slower, and consequently, the conductivity change reduced. Theoretically, the dehydrated radius of $\mathrm{Na}^{+}$is around $0.95 \AA$ [21,23], which is smaller than the ZIF-8 pores (3.4 $\AA$ ). Therefore, a small addition of ZIF- 8 to the TFN increased the $\mathrm{Na}^{+}$flux. With a higher ZIF-8 loading in the surface selective layer, the $\mathrm{Na}^{+}$flux further increases, which may be caused by two reasons. First, increased ZIF-8 loadings introduce more free space that can facilitate the $\mathrm{Na}^{+}$migration. More importantly, the structural changes with ZIF-8 incorporation and the possible voids between the organic/inorganic interphase could facilitate the $\mathrm{NaCl}$ permeance $[17,33]$.

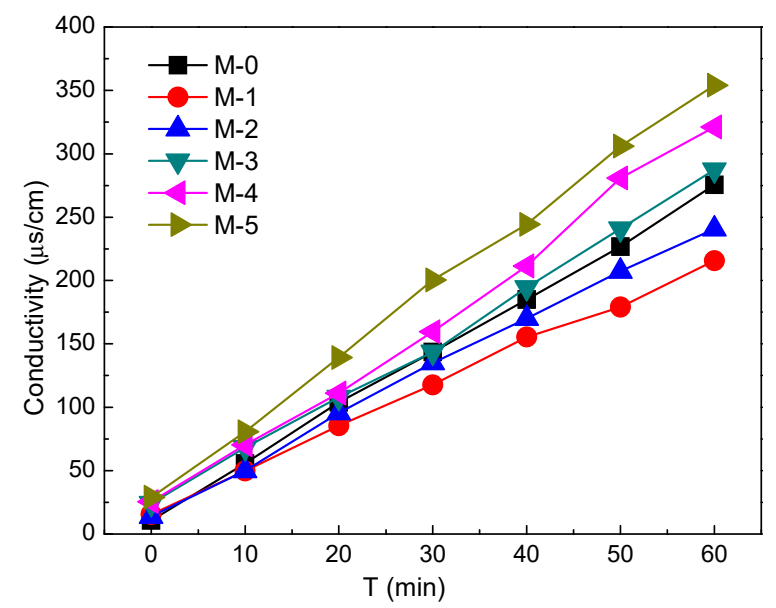

Figure 6. Conductivity change of diluate compartment during diffusion process. 


\subsection{Membrane Resistance}

Electrochemical impedance spectroscopy is an important tool to elucidate the electrochemical parameters of a membrane, allowing for quantifying the resistance of the membrane matrix. As can be observed in Figure 7, for M-0 membrane, the membrane resistance increased by a factor 1.5 for $\mathrm{MgCl}_{2}$ when compared to the $\mathrm{NaCl}$ solution. The increased resistance for $\mathrm{NaCl}$ solution indicates that the presence of the MPD/TMC layer near the cation-exchange membrane hinders the ionic transport. Since the similar IEC and water uptake yield a relative constant resistance, which means that the transport of $\mathrm{Na}^{+}$is not much affected by the ZIF-8 incorporation. In the case of $\mathrm{Mg}^{2+}$, the reduction of membrane resistance was observed, because carboxylic acids are inert diluents that the interaction between $\mathrm{Mg}^{2+}$ was greatly mitigated. As a consequence, $\mathrm{Mg}^{2+}$ permeates through the cation-exchange membrane becomes easier and the membrane resistance reduced. The variation of resistance with ZIF-8 content on the membrane surface was large. Since the incorporation of ZIF-8 would increase the water uptake, in this regard, the further enhancement of membrane conductivity is produced. However, with the increase ZIF-8 loading to a certain content, the membrane resistance continuous increasing. In this condition, the steric hinderance effect of ZIF-8 and enhanced crosslinking play a much more important role, rather than electrostatic effect. In contrast, while ZIF-8 loading reached $0.8 \%$, higher filler concentration caused the unselective voids with a significant drop in rejection, as a result, membrane resistance in $\mathrm{MgCl}_{2}$ solution drops again.
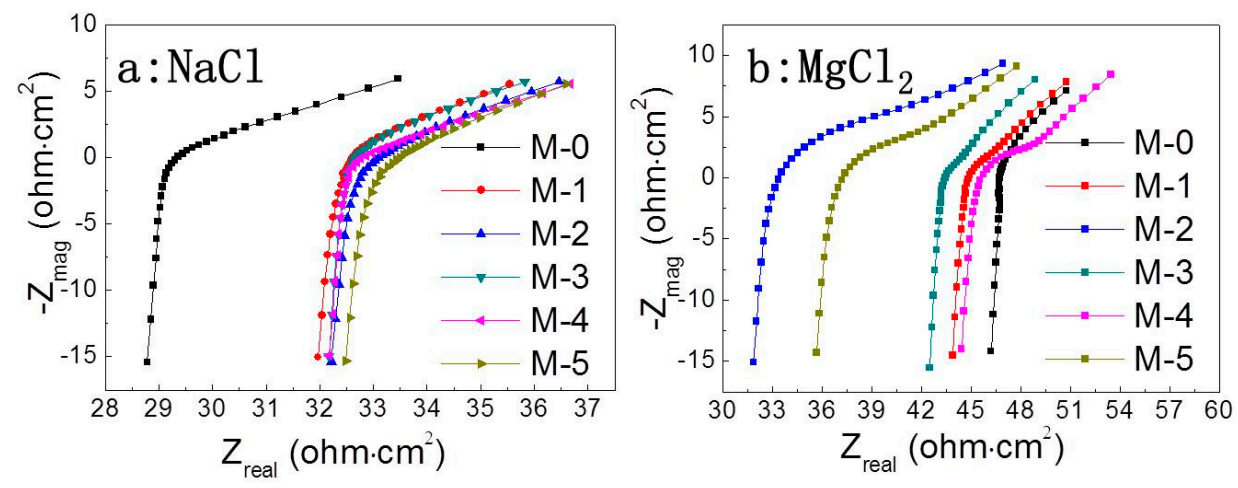

Figure 7. ZIF-8 effect on electrochemical impedance spectroscopy (EIS) of membrane for $\mathrm{NaCl}$ and $\mathrm{MgCl}_{2}$ solutions. ((a) EIS results obtained in $\mathrm{NaCl}$ solution; (b) EIS results obtained in $\mathrm{MgCl}_{2}$ solution)

\subsection{Electrodialysis Experiments}

The electrochemical behavior of the modified membranes was investigated by electrodialysis using single $\mathrm{NaCl}$ and $\mathrm{MgCl}_{2}$ systems. During the $\mathrm{NaCl}$ desalination experiment, $2 \mathrm{~g} / \mathrm{L} \mathrm{NaCl}$ was used as diluate and concentrate compartment, respectively, while it is replaced by $2 \mathrm{~g} / \mathrm{L} \mathrm{MgCl} 2$ during the $\mathrm{MgCl}_{2}$ desalination experiment. $1 \mathrm{~L} 20 \mathrm{~g} / \mathrm{L} \mathrm{Na}_{2} \mathrm{SO}_{4}$ was used as the electrode rinsing solution with a current density of $15.3 \mathrm{~mA} \mathrm{~cm}^{-2}$. The conductivity of the diluate compartment decreased with desalination time for both systems (Figure 8). No obvious variation on desalination performance can be observed after surface modification and incorporation of nanoparticles. For ED, constant-current or constant-voltage major can be applied as operating modes. In previous studies using a constant-voltage strategy, the conductivity of the diluate compartment continually decreased. The elevated system resistance, and thus lower current density, retards the transfer of ions through the ion exchange membrane. Since a constant-current system could maintain a stable current, the effect of current density variation on concentration change of the diluate compartment would be expected to be minimized. In order to obtain a better understanding of this specific process, the concentrations of $\mathrm{Na}^{+}$and $\mathrm{Mg}^{2+}$ at 15 min were considered to calculate the cation flux, due to the fact that the voltage of the system would exceed the maximum voltage of the power supply after $15 \mathrm{~min}$. It can be seen from Figure $8 \mathrm{c}$ that a reduction of the $\mathrm{Na}^{+}$and $\mathrm{Mg}^{2+}$ ion flux after surface modification 
is obtained. Conversely, a higher $\mathrm{Na}^{+}$transport and a smaller $\mathrm{Mg}^{2+}$ transport were found after introducing the ZIF-8 nanoparticles. Generally, the increased IEC could facilitate the transport of $\mathrm{Na}^{+}$and $\mathrm{Mg}^{2+}$ transport, however, ZIF- 8 under the PA surface layer could hinder the $\mathrm{Mg}^{2+}$ transport. The results were different from previous results, which were carried out by incorporating Mil53-(Al) nanoparticles [34]. The free diameter of Mil53-(Al) is close to $0.85 \mathrm{~nm}$, which makes it easier to transfer $\mathrm{Na}^{+}$and $\mathrm{Mg}^{2+}$ than ZIF-8. With more ZIF-8 being incorporated into the membrane matrix, both the $\mathrm{Na}^{+}$and $\mathrm{Mg}^{2+}$ transport was increased, which can be explained by the higher IEC and the formation of unselective voids. When compared with the membrane with Mil53-(Al), the interfacial polymerization with ZIF-8 method provides an enhanced IEC and diffusion ability with a lower water uptake. Furthermore, a higher electro-resistance to $\mathrm{Mg}^{2+}$ ions could impose the membrane with the possibility to separate monovalent ions. The energy consumption that was required during the ED process was also considered (Figure 8d). The energy consumption was found to decrease with increasing ZIF-8 loadings, which confirmed the facilitated migration of cations.
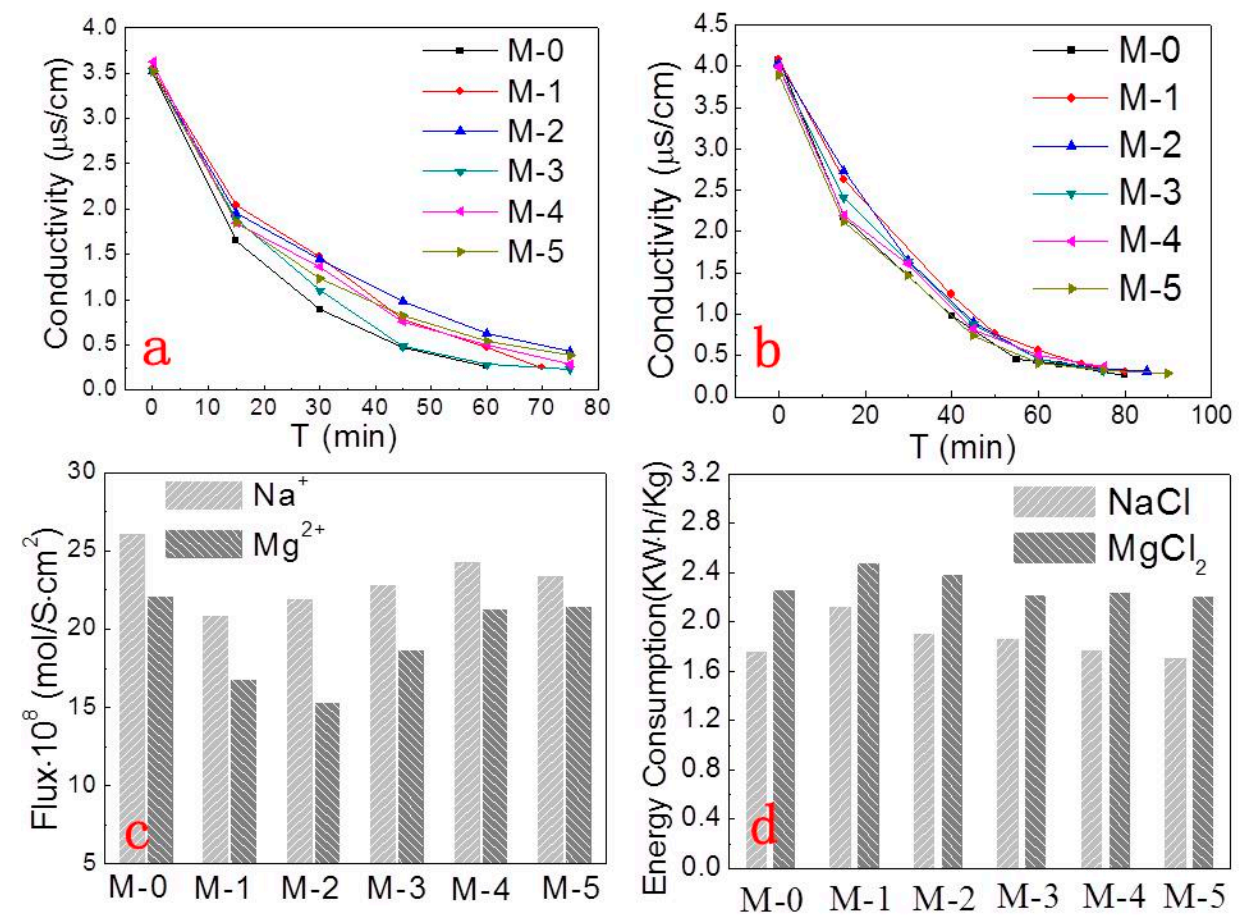

Figure 8. (a) Conductivity change of diluate compartment for Sodium chloride ( $\mathrm{NaCl})$ system; (b) Conductivity change of diluate compartment for the magnesium chloride $\left(\mathrm{MgCl}_{2}\right)$ system; (c) Flux of ions in $15 \mathrm{~min}$; and, (d) Energy consumption for different systems.

\subsection{Monovalent Selectivity}

For the separation of monovalent and divalent cations, a comparison of monovalent and multivalent cations fluxes is presented in Figure 9. In the binary mixtures, MPD/TMC modified membranes show a much lower $\mathrm{Na}^{+}$and $\mathrm{Mg}^{2+}$ flux than the untreated membrane, demonstrating the improvement of the steric hindrance effect. Simultaneously, the monovalent selectivity of the modified membrane increased from 1.77 to 3.66. Particularly, with incorporating ZIF-8 nanoparticles, the monovalent selectivity notably increased to 4.03 . However, the flux of $\mathrm{Na}^{+}$was reduced, which is different from the observations in single salt desalination. The larger affinity of $\mathrm{Mg}^{2+}$ for the ion exchange groups inside the membrane matrix would allow for them to occupy more ions exchange transfer sites; as a consequence, a strong suppression was imposed on the transfer of $\mathrm{Na}^{+}$ions. Furthermore, the more hydrophobic membrane surface could reduce the permeation of strongly hydrated cations, while facilitating the less hydrated ones [35]. Combining the contribution of the 
dense MPD/TMC layer as well as the size sieving effect of ZIF-8, the monovalent selectivity was greatly enhanced. Further increasing the ZIF-8 content has no obvious effect on the monovalent selectivity; however, in this case, the both the $\mathrm{Na}^{+}$and the $\mathrm{Mg}^{2+}$ permeance increased. In this condition, the increased amount of ZIF-8 reduced the thickness of the dense surface, which would also contribute to the increase of the ion flux. For M-5, although the transfer resistance was further decreased, the voids facilitated both the $\mathrm{Na}^{+}$and $\mathrm{Mg}^{2+}$ migration from the membrane matrix to the solution. In this case, a lower monovalent selectivity was obtained.

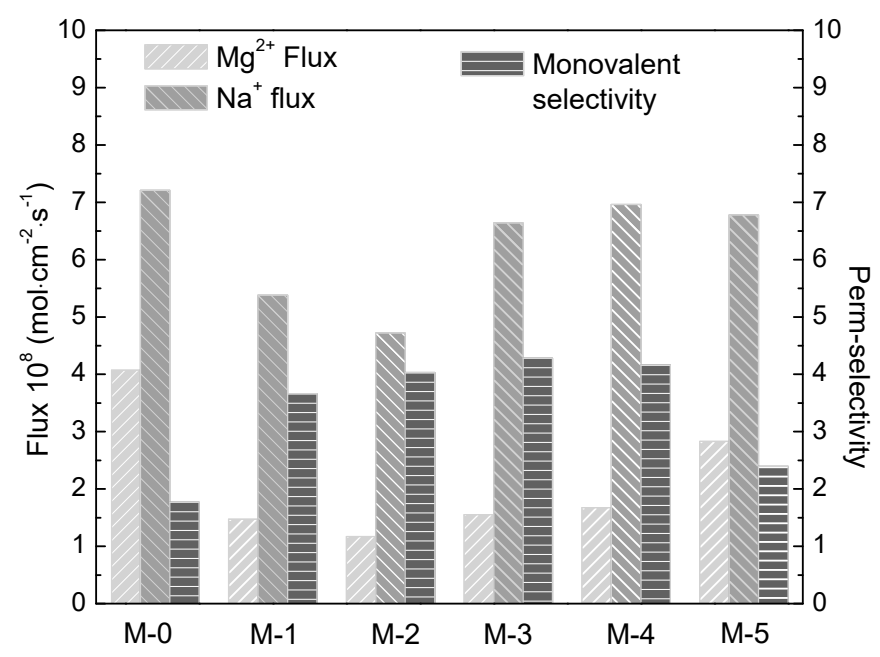

Figure 9. The ion flux and monovalent selectivity of $\mathrm{Na}^{+} / \mathrm{Mg}^{2+}$ system during electrodialysis (ED).

\section{Conclusions}

ZIF-8 was successfully anchored under the skin layer of commercial ion exchange membranes by interfacial polymerization. The monovalent selectivity of the modified membrane increased from 1.77 to 4.03 , which is more than a twofold increase. Furthermore, during the separation process, the $\mathrm{Na}^{+}$flux maintained a similar level when compared to the primary membrane, while the $\mathrm{Mg}^{2+}$ flux was significantly reduced. When single salt solution desalination experiments were conducted, the ZIF-8 incorporation could decrease the energy consumption by facilitating ion transport. When considering the increased monovalent selectivity and $\mathrm{Na}^{+}$flux, introducing nanoparticles to the surface functional layer could be a promising way to enhance the ion flux in monovalent ion exchange membrane applications.

Author Contributions: Conceptualization, J.L.; Methodology, J.L.; Software, Z.Z.; Validation, J.Z., S.Y. and B.V.d.B.; Formal Analysis, J.L.; Investigation, J.L.; Resources, S.Y.; Data Curation, J.Z.; Writing-Original Draft Preparation, J.L.; Writing-Review \& Editing, J.Z.; Visualization, B.V.d.B.; Supervision, B.V.d.B.; Project Administration, B.V.d.B.; Funding Acquisition, B.V.d.B.

Conflicts of Interest: The authors declare no conflict of interest.

\section{References}

1. Johnson, R.J.; Stenvinkel, P.; Jensen, T.; Lanaspa, M.A.; Roncal, C.; Song, Z.; Bankir, L.; Sánchez-Lozada, L.G. Metabolic and kidney diseases in the setting of climate change, water shortage, and survival factors. J. Am. Soc. Nephrol. 2016, 27, 2247-2256. [CrossRef] [PubMed]

2. Pendergast, M.M.; Hoek, E.M. A review of water treatment membrane nanotechnologies. Energy Environ. Sci. 2011, 4, 1946-1971. [CrossRef]

3. Liu, J.; Yang, H.; Gosling, S.N.; Kummu, M.; Flörke, M.; Pfister, S.; Hanasaki, N.; Wada, Y.; Zhang, X.; Zheng, C. Water scarcity assessments in the past, present and future. Earths Future 2017, 5, 545-559. [CrossRef]

4. Khawaji, A.D.; Kutubkhanah, I.K.; Wie, J.-M. Advances in seawater desalination technologies. Desalination 2008, 221, 47-69. [CrossRef] 
5. Lattemann, S.; Höpner, T. Environmental impact and impact assessment of seawater desalination. Desalination 2008, 220,1-15. [CrossRef]

6. Elimelech, M.; Phillip, W.A. The future of seawater desalination: Energy, technology, and the environment. Science 2011, 333, 712-717. [CrossRef] [PubMed]

7. Ge, L.; Wu, B.; Yu, D.; Mondal, A.N.; Hou, L.; Afsar, N.U.; Li, Q.; Xu, T.; Miao, J.; Xu, T. Monovalent cation perm-selective membranes (MCPMs): New developments and perspectives. Chin. J. Chem. Eng. 2017, 25, 1606-1615. [CrossRef]

8. Ge, L.; Wu, B.; Li, Q.; Wang, Y.; Yu, D.; Wu, L.; Pan, J.; Miao, J.; Xu, T. Electrodialysis with nanofiltration membrane (EDNF) for high-efficiency cations fractionation. J. Membr. Sci. 2016, 498, 192-200. [CrossRef]

9. Lau, W.; Gray, S.; Matsuura, T.; Emadzadeh, D.; Chen, J.P.; Ismail, A. A review on polyamide thin film nanocomposite (TFN) membranes: History, applications, challenges and approaches. Water Res. 2015, 80, 306-324. [CrossRef] [PubMed]

10. Amini, M.; Jahanshahi, M.; Rahimpour, A. Synthesis of novel thin film nanocomposite (TFN) forward osmosis membranes using functionalized multi-walled carbon nanotubes. J. Membr. Sci. 2013, 435, $233-241$. [CrossRef]

11. Safarpour, M.; Khataee, A.; Vatanpour, V. Thin film nanocomposite reverse osmosis membrane modified by reduced graphene oxide $/ \mathrm{TiO}_{2}$ with improved desalination performance. J. Membr. Sci. 2015, 489, 43-54. [CrossRef]

12. Peyravi, M.; Jahanshahi, M.; Rahimpour, A.; Javadi, A.; Hajavi, S. Novel thin film nanocomposite membranes incorporated with functionalized $\mathrm{TiO}_{2}$ nanoparticles for organic solvent nanofiltration. Chem. Eng. J. 2014, 241, 155-166. [CrossRef]

13. Kitagawa, S. Metal-organic frameworks (MOFs). Chem. Soc. Rev. 2014, 43, 5415-5418.

14. Sorribas, S.; Gorgojo, P.; Téllez, C.; Coronas, J.; Livingston, A.G. High flux thin film nanocomposite membranes based on metal-organic frameworks for organic solvent nanofiltration. J. Am. Chem. Soc. 2013, 135, 15201-15208. [CrossRef] [PubMed]

15. Van Goethem, C.; Verbeke, R.; Hermans, S.; Bernstein, R.; Vankelecom, I. Controlled positioning of MOFs in interfacially polymerized thin-film nanocomposites. J. Mater. Chem. A 2016, 4, 16368-16376. [CrossRef]

16. Wee, L.H.; Lescouet, T.; Ethiraj, J.; Bonino, F.; Vidruk, R.; Garrier, E.; Packet, D.; Bordiga, S.; Farrusseng, D.; Herskowitz, M.; et al. Hierarchical Zeolitic Imidazolate Framework-8 Catalyst for Monoglyceride Synthesis. ChemCatChem 2013, 5, 3562-3566. [CrossRef]

17. Duan, J.; Pan, Y.; Pacheco, F.; Litwiller, E.; Lai, Z.; Pinnau, I. High-performance polyamide thin-film-nanocomposite reverse osmosis membranes containing hydrophobic zeolitic imidazolate framework-8. J. Membr. Sci. 2015, 476, 303-310. [CrossRef]

18. Wang, L.; Fang, M.; Liu, J.; He, J.; Li, J.; Lei, J. Layer-by-layer fabrication of high-performance polyamide/ZIF-8 nanocomposite membrane for nanofiltration applications. ACS Appl. Mater. Interfaces 2015, 7, 24082-24093. [CrossRef] [PubMed]

19. Shi, G.M.; Yang, T.; Chung, T.S. Polybenzimidazole (PBI)/zeolitic imidazolate frameworks (ZIF-8) mixed matrix membranes for pervaporation dehydration of alcohols. J. Membr. Sci. 2012, 415, 577-586. [CrossRef]

20. Bazinet, L.; Moalic, M. Coupling of porous filtration and ion-exchange membranes in an electrodialysis stack and impact on cation selectivity: A novel approach for sea water demineralization and the production of physiological water. Desalination 2011, 277, 356-363. [CrossRef]

21. Kang, K.C.; Linga, P.; Park, K.-N.; Choi, S.-J.; Lee, J.D. Seawater desalination by gas hydrate process and removal characteristics of dissolved ions $\left(\mathrm{Na}^{+}, \mathrm{K}^{+}, \mathrm{Mg}^{2+}, \mathrm{Ca}^{2+}, \mathrm{B}^{3+}, \mathrm{Cl}^{-}, \mathrm{SO}_{4}^{2-}\right)$. Desalination 2014, 353, 84-90. [CrossRef]

22. Kotov, V.; Peregonchaya, O.; Selemenev, V. Electrodialysis of binary electrolyte mixtures with membranes modified by organic species. Russ. J. Electrochem. 2002, 38, 927-929. [CrossRef]

23. Tansel, B.; Sager, J.; Rector, T.; Garland, J.; Strayer, R.F.; Levine, L.; Roberts, M.; Hummerick, M.; Bauer, J. Significance of hydrated radius and hydration shells on ionic permeability during nanofiltration in dead end and cross flow modes. Sep. Purif. Technol. 2006, 51, 40-47. [CrossRef]

24. Firdaous, L.; Malériat, J.P.; Schlumpf, J.P.; Quéméneur, F. Transfer of monovalent and divalent cations in salt solutions by electrodialysis. Sep. Sci. Technol. 2007, 42, 931-948. [CrossRef]

25. Han, L.; Galier, S.; Balmann, H.R. Ion hydration number and electro-osmosis during electrodialysis of mixed salt solution. Desalination 2015, 373, 38-46. [CrossRef] 
26. Li, J.; Yuan, S.; Wang, J.; Zhu, J.; Shen, J.; van der Bruggen, B. Mussel-inspired modification of ion exchange membrane for monovalent separation. J. Membr. Sci. 2018, 553, 139-150. [CrossRef]

27. Sun, F.; Wu, C.; Wu, Y.; Xu, T. Porous BPPO-based membranes modified by multisilicon copolymer for application in diffusion dialysis. J. Membr. Sci. 2014, 450, 103-110. [CrossRef]

28. Lind, M.L.; Ghosh, A.K.; Jawor, A.; Huang, X.; Hou, W.; Yang, Y.; Hoek, E.M. Influence of zeolite crystal size on zeolite-polyamide thin film nanocomposite membranes. Langmuir 2009, 25, 10139-10145. [CrossRef] [PubMed]

29. Wang, L.; Fang, M.; Liu, J.; He, J.; Deng, L.; Li, J.; Lei, J. The influence of dispersed phases on polyamide/ZIF-8 nanofiltration membranes for dye removal from water. RSC Adv. 2015, 5, 50942-50954. [CrossRef]

30. Erbil, H.Y.; Demirel, A.L.; Avc1, Y.; Mert, O. Transformation of a simple plastic into a superhydrophobic surface. Science 2003, 299, 1377-1380. [CrossRef] [PubMed]

31. Nabe, A.; Staude, E.; Belfort, G. Surface modification of polysulfone ultrafiltration membranes and fouling by BSA solutions. J. Membr. Sci. 1997, 133, 57-72. [CrossRef]

32. Kang, G.-D.; Cao, Y.-M. Development of antifouling reverse osmosis membranes for water treatment: A review. Water Res. 2012, 46, 584-600. [CrossRef] [PubMed]

33. Chung, T.-S.; Jiang, L.Y.; Li, Y.; Kulprathipanja, S. Mixed matrix membranes (MMMs) comprising organic polymers with dispersed inorganic fillers for gas separation. Prog. Polym. Sci. 2007, 32, 483-507. [CrossRef]

34. Li, J.; Zhu, J.; Yuan, S.; Li, X.; Zhao, Z.; Zhao, Y.; Liu, Y.; Volodine, A.; Li, J.; Shen, J.; et al. Mussel-inspired monovalent selective cation exchange membranes containing hydrophilic mil53 (al) framework for enhanced ion flux. Ind. Eng. Chem. Res. 2018, 57, 6275-6283. [CrossRef]

35. Sata, T. Studies on anion exchange membranes having permselectivity for specific anions in electrodialysis-Effect of hydrophilicity of anion exchange membranes on permselectivity of anions. J. Membr. Sci. 2000, 167, 1-31. [CrossRef]

(C) 2018 by the authors. Licensee MDPI, Basel, Switzerland. This article is an open access article distributed under the terms and conditions of the Creative Commons Attribution (CC BY) license (http:/ / creativecommons.org/licenses/by/4.0/). 